\title{
NAVEGAR SEM LER, LER SEM NAVEGAR E OUTRAS COMBINAC̣̃̃ES DE HABILIDADES DO LEITOR
}

\section{Ana Elisa Ribeiro*}

Resumo: Com base nos conceitos de letramento, sistema de mídia e mídias mosaiquicas e apoiado em uma concepção de hipertexto não exclusivamente digital, este trabalho mostra a relação de grupos de leitores com a leitura de jornais impressos e digitais. Este estudo de caso foi desenvolvido com alunos de uma instituição privada de ensino superior, em Belo Horizonte. Após a aplicação de questionários sobre hábitos e frequência de leitura de jornais, foram selecionados 23 alunos para fazer testes de navegação e leitura. Algumas habilidades de leitura foram medidas com base na matriz de Língua Portuguesa do Saeb. Com base nos resultados, faz-se a diferenciação entre habilidades de navegação e habilidades de leitura. Os resultados também sugerem certa assimetria entre navegação e leitura (compreensão), já que nem sempre os navegadores mais hábeis compreendem o que leem, assim como nem sempre aqueles que mostram dificuldades em navegar têm mau desempenho em leitura. Conclui-se que a leitura se constrói a partir de uma sobreposição complexa de habilidades. Embora seja importante que o leitor desenvolva letramentos vários, é possível apresentar habilidades assimétricas em relação a diferentes aspectos da leitura.

Palavras-chave: Letramento digital; Hipertexto; Jornalismo digital; Habilidades de leitura.

\section{NAVIGATING WITHOUT READING, READING WITHOUT NAVIGATING AND OTHER COMBINATIONS OF READERS ABILITIES}

ABSTRACT: Based upon the concepts of literacy, media systems and mosaic media, supported by an off-line concept of hypertext, this work discusses the relationship established by readers groups with the reading of newspapers. This case study was carried out with undergraduates at a private school in Belo Horizonte. From questionnaire-generated reading profiles, a group of 23 students was selected to make tests on navigation and on reading. The sudents had to answer questions, which were proposed in accordance with Saeb exam reading abilities matrix. The results show that good navigators may be low proficient readers and good readers may be poor navigators. So, it was possible to conclude that reading depends upon the development of many other abilities, independently of the reading platform; that reading is built up from a complex superposition of abilities.

Keywords: Digital Literacy; Hypertext; Digital Journalism; Reading abilities.

\footnotetext{
* Doutora em Linguística Aplicada (Linguagem e Tecnologia) pela Universidade Federal de Minas Gerais (UFMG); Professora do Mestrado em Estudos de Linguagens no Centro Federal de Educação Tecnológica de Minas Gerais (CEFET/MG); Coordenadora do Laboratório de Pesquisa em Leitura e Cognição do Centro Federal de Educação Tecnológia de Minas Gerais (CEFET/MG).E-mail: anadigital@gmail.com
} 


\section{Consideraç̃ões iniciais}

De pé, desfiando o texto em direção horizontal, ou em recinto fechado, folheando um códice pesado; ao ar livre ou em um gabinete, absorvido pelo livro portátil, ou sentado, com as pernas encolhidas sob um teclado e os olhos vidrados na luz do monitor. Todos esses gestos, embora se tenham tornado possíveis com o passar do tempo, não se excluíram necessariamente. O que se quer dizer, portanto, é que cumulativamente, o leitor atual conhece mais práticas de ler do que um leitor de séculos atrás. Não apenas por isso, é possível afirmar que existem leitores, que aprendem gestos ao longo dos tempos, em contato com práticas configuradas pela conjunção de técnicas e dispositivos dos quais usufrui. Esse usufruto, no entanto, é aprendido. Cada objeto de ler é apropriado pelo leitor, que aprende uma espécie de "protocolo", sequências mais ou menos rígidas de leitura de textos (em objetos). Diante do rolo de couro animal, ainda que quisesse, leitor algum poderia folhear. Certamente, na mudança deste modo de ler para outro, algum leitor reclamou saudades do gesto de abrir um rolo. Com a aceitação das folhas empilhadas e costuradas, foi possível folhear. Mais tarde, em decorrência disso, foi possível numerar páginas, escrever dos dois lados do papel (ou do couro) e navegar por índices e sumários. Gestos e habilidades, no entanto, têm se confundido e, muitas vezes, têm sido tratados como sinônimos.

Nos dias de hoje, o leitor tem, ao menos potencialmente, vários dispositivos para ler, incluindo-se aí modos híbridos, genealogicamente ligados a outros (BOLTER; GRUSIN, 2000; até mesmo SNYDER, 2001). Ler sumários, investigar índices ou encontrar páginas são habilidades desenvolvidas com base na existência de objetos navegáveis. Localizar informações é habilidade fundamental para operar em ambientes (impressos ou digitais), mas, para alcançá-la, não basta saber navegar, é preciso saber ler e selecionar, estas, sim, habilidades cognitivas. É dessa interpolação entre gestos e habilidades que trata o relato desta pesquisa, desenvolvida de 2005 a 2008, na Faculdade de Letras da Universidade Federal de Minas Gerais (UFMG).

Uma das questões que mais parece inquietar pesquisadores da linguagem e da leitura é em que medida novas práticas de ler e escrever afetam/alteram/influenciam a cognição do novo leitor. Neste artigo, pretendemos apresentar, embora ligeiramente, os resultados de uma 
pesquisa cujo intento foi responder a questões relativas às estratégias (e táticas) de leitores pouco letrados, especialmente na leitura de jornais, especialmente quanto às distinções entre navegar e ler.

\subsection{Conceitos importantes}

Se há um conceito do qual é imprescindível tratar neste trabalho é o de letramento. Juntamente com ele, o de agência de letramento, assim como a compreensão inequívoca de que existem práticas de leitura, em um sistema de mídia cada vez mais complexo. Segundo Briggs e Burke (2004), o sistema de mídia é um regime em que o leitor/usuário se apropria muito lentamente das técnicas recém-chegadas, nem sempre para substituir outras.

Pensar em termos de um sistema de mídia significa enfatizar a divisão de trabalho entre os diferentes meios de comunicação disponíveis em um certo lugar e em um determinado tempo, sem esquecer que a velha e a nova mídia podem e realmente coexistem, e que diferentes meios de comunicação podem competir entre si ou imitar um ao outro, bem como se complementar. (BRIGGS; BURKE, 2004, p. 33)

No início da Idade Média, o sistema de mídia ocidental contava com poucas opções. O leitor da atualidade dispõe de muito mais formatos de texto, em suportes os mais diversos. Se alguns conflitos desapareceram, outros surgiram. Do ponto de vista do leitor, as práticas também se alteraram. E para aqueles com quem isso ainda não aconteceu, ao menos podem saber que os horizontes certamente se alargaram.

O letramento está relacionado aos usos efetivos que as pessoas fazem da alfabetização que tiveram. Os diversos espaços que orientam as práticas de indivíduos e comunidades para letramentos diversos são chamados de agências de letramento. Pessoas e comunidades podem ser letradas em espaços diversos e por meio de práticas as mais distintas. A partir das agências, um leitor pode se tornar letrado em vários níveis, que são o que Kleiman (1995) e Tfouni (2004) chamam de graus de letramento. Não há limites para o letramento uma vez que a humanidade sempre inventará formas novas de escrever, novos gêneros de texto, suportes de leitura, etc., de acordo com as infinitas necessidades que temos e teremos. A Internet e as máquinas digitais estão entre nossas opções mais recentes. 
A relação entre os dispositivos para a comunicação foi recentemente reconfigurada, consequentemente, as possibilidades e as exigências do letramento, também.

\subsection{Hipertextos e leitura de jornais}

Uma das características mais importantes e mais debatidas do hipertexto é a não-linearidade de sua arquitetura, que enseja a ação nãolinear de leitura pelo "usuário". No lugar da larga coluna na página ou mesmo de colunas paralelas, o texto estaria organizado em blocos menores, apenas parcialmente aparentes. Cada bloco seria o começo (ou o fim) de outro e entre eles haveria um acesso possível (ou vários), o link². Esse modo de apresentar textos, em que o leitor vê uma face da obra, mas não tem acesso direto às outras, desencadeia uma discussão que já data de décadas. É possível encontrar quem defina o hipertexto por essa característica e quem diga que isso já existia muito antes de os computadores serem inventados. A não-linearidade é, para alguns, uma premissa. Para outros, é importante, mas não suficiente para se classificar um texto como hipertexto. Para citar alguns, Xavier (2004) e Soares (2002), por exemplo, afirmam ser necessário estar em ambiente digital para que um texto não-linear seja um hipertexto. Outros tantos pesquisadores preferem considerar, genealogicamente, como Bolter e Grusin (2000), que hipertextos já existem há quase um milênio. Para estes, sumários e notas de rodapé levam o leitor à navegação e podem ser a realização primária dos links, já que, funcionalmente, acionam nãolinearidades num texto, mesmo estando ele em papel (p. ex. LÉVY, 1993; CHARTIER, 2001a e 2001b).

Neste trabalho, assume-se a perspectiva daqueles que entendem que os hipertextos já existiam em meios anteriores aos digitais. E é essa escolha teórica, baseada na concepção que se tem dos objetos impressos de ler cujas arquiteturas de texto não são lineares, é que permite incluir os jornais entre os hipertextos.

Silva (2002), por exemplo, cita Marcuschi para defender a hipertextualidade como uma "estratégia de organização textual, já que muitos gêneros podem aparecer num formato hipertextual”. A primeira página do jornal impresso é, para a autora, exemplo de texto descontínuo, índice de páginas internas, "segmentos textuais conectados". 
Considerando as chamadas de primeira página como links (embora de natureza não-digital), é possível considerar que "o leitor de jornal, à semelhança do 'navegador', pode definir o fluxo de sua leitura, sem se prender a uma seqüência típica" (SILVA, 2002). "O texto jornalístico também se apresenta de forma fragmentária, se levarmos em consideração que a própria diagramação do jornal é uma espécie de 'colcha de retalhos', constituída por estruturas temáticas bem diversificadas" (SILVA, 2002).

Os jornais têm a forma de um mosaico, em que o leitor seleciona o que quer ler e concebe uma ordem de leitura a partir de necessidades e preferências. Para Santaella (2004), citando Holtzman (1997, p. 30-31. Grifos nossos), “o movimento para a expressão alinear, que caracteriza a hipermídia, não emergiu do nada. Seus primeiros sinais já se deram em 1844, quando da invenção do telégrafo, que catalisou o desenvolvimento das mídias mosaiquicas (expressão cunhada por McLuhan), de que o jornal foi um dos primeiros exemplares".

Ler um jornal pressupõe a aprendizagem de gestos descontínuos e seletivos. Com a prática, o leitor ganha habilidades que outros suportes dispensam: escanear a primeira página, observar numeração, saber o que é principal e o que é secundário na diagramação da notícia, relacionar o texto lido hoje a outro anterior. O conceito de mídia mosaiquica é fundamental neste trabalho. Esse tipo mídia promove, desde seu planejamento, uma leitura alinear e personalizada ("customizada", como preferem alguns webdesigners) e está genealogicamente relacionado a outros ambientes.

\section{Métodos e instrumentos de pesquisa}

Com base nos conceitos citados e em pesquisa empírica, passamos a relatar os resultados da pesquisa desenvolvida com um grupo de alunos de instituição privada de ensino superior, em Belo Horizonte. Temos, aqui, a intenção de compreender melhor determinado aspecto da leitura, sem a pretensão de generalizar os resultados observados. AlvesMazzotti (2006), citando Stake (2000), chama a este tipo de pesquisa o "caso instrumental", ou seja, aquele cujo interesse "deve-se à crença de que ele poderá facilitar a compreensão de algo mais amplo, uma vez que 
pode servir para fornecer insights sobre um assunto ou para contestar uma generalização amplamente aceita" (ALVES-MAZZOTTI, 2006, p. 641642). Vamos considerar que os grupos de leitores deste trabalho possam dar uma ideia de tipicidade no comportamento de leitores de jornais em ambientes impressos e digitais.

\subsection{Grupos de leitores de jornal}

Iniciamos a investigação pela proposta de conhecer o perfil de leitores dos alunos do primeiro período do curso de Enfermagem. O curso foi escolhido por estar, naquele momento, atravessando uma fase de grande procura, com muitos alunos recém-chegados, grande parte deles oriunda de camadas desfavorecidas da sociedade e com baixo grau de letramento.

Inspiradas na pesquisa Retrato da Leitura no Brasil (ANGIOLOLLO, 2001), propusemos um questionário misto (perguntas de múltipla escolha e abertas), que foi aplicado a todas as turmas do primeiro período. $\mathrm{O}$ intento era conhecer, por meio das respostas dos alunos, seus hábitos e frequência de leitura, especialmente de jornais impressos e on-line ${ }^{3}$.

Dos formulários aplicados, 144 foram respondidos e devolvidos ${ }^{4}$. Com base nessas respostas, foi possível distinguir quatro grupos de leitores mais frequentes: Grupo 1 - Leitores de jornais impressos, mas não de digitais; Grupo 2 - Leitores de jornais digitais, mas não de impressos; Grupo 3 - Não-leitores de jornais; e Grupo 4 - Leitores de jornais impressos e digitais.

O Grupo 4 era formado por um perfil de leitor já pesquisado em investigação anterior, com resultados amplamente publicados, inclusive em Educação em Revista 5 . Por essa razão, ativemo-nos aos outros três perfis, de cujos grupos selecionamos, inicialmente, 30 alunos para participar dos testes de navegação/leitura compostos a partir de tarefas a serem cumpridas durante a leitura de jornais impressos e digitais. Para a composição dessas tarefas, empregamos métodos inspirados nos testes de usabilidade da Ciência da Computação ${ }^{6}$ e na matriz de habilidades de leitura do Sistema de Avaliação da Educação Básica (Saeb).

De fato, 23 alunos executaram os testes. O grupo 1 era composto por 11 estudantes e os grupos 2 e 3 tinham, respectivamente, 7 
e 5 representantes. Os jornais escolhidos para os testes foram Estado de Minas e $O$ Tempo, que dispõem de versões na internet. Em 5 de agosto de 2006, compramos a versão impressa de cada um dos jornais e fizemos a captura de suas versões digitais em CD. Os leitores poderiam manipulálos em papel e em tela da mesma forma, em ambientes autênticos. De posse desse material, planejamos as tarefas de navegação e selecionamos os textos para leitura.

Pela classificação de Mielniczuk (2001), estes jornais são pouco mais do que simples transposições ${ }^{7}$, encontram-se em um estágio em que empregam links e certa interatividade, mas não chegam a ser ambientes completamente divorciados de seus projetos impressos. Essa característica de identidade entre o impresso e o digital tem sido empregada como estratégia das empresas jornalísticas para facilitar a adesão do leitor à leitura em meio digital, no entanto, subaproveita características genuinamente digitais do ambiente. Nossa preferência por este tipo de ambiente deveu-se justamente à intenção de oferecer ao aluno com o qual trabalharíamos algum conforto ou familiaridade em relação à interface. Um projeto webjornalístico muito inovador poderia oferecer tantos obstáculos à navegação que nossos resultados seriam previsíveis já em relação à usabilidade da interface. É interessante, no entanto, mencionar que testes com interfaces digitais inovadoras podem ensejar novas investigações sobre leitura e navegação.

\subsection{Notícias impressas e digitais}

Os jornais que utilizamos na pesquisa, em tamanho standard, são constituídos por vários cadernos que correspondem às editorias. Ambos apresentam primeira página em mosaico, com chamadas para matérias internas. A manchete ocupa o lugar mais evidente na página e as demais notícias se compõem em laterais, embaixo, em pontos menos ou mais visíveis pelo leitor (Ver Apêndices 1 e 2).

As notícias selecionadas eram idênticas nas duas versões dos diários. Os meios distintos em que elas se encontravam ensejavam gestos diferentes por parte do leitor: o link em lugar da referência simples motivava o clique em lugar do folhear. Afora os gestos solicitados por um ou outro ambiente, as habilidades de leitura demandadas pelos textos seriam apuradas nas mesmas notícias, em ambas as interfaces. 
Escolhemos duas notícias de cada jornal, ambas relacionadas a fatos do cotidiano da cidade de Belo Horizonte, onde todos os estudantes residiam, trabalhavam ou estudavam. Dessa forma, pensamos minimizar problemas gerados pela falta de conhecimento prévio ou informações compartilhadas entre jornalista e leitor.

No Estado de Minas e n'O Tempo, as chamadas contêm indicação de página. Os jornais são numerados e impressos em cores, com textos e fotos. O Estado de Minas de 5 de agosto era formado por 7 cadernos: Primeiro, Gerais, Informática, Cultura, Classificados, Esportes e Imóveis. As páginas eram numeradas, sendo que os cadernos Primeiro, Gerais e Esportes tinham numeração contínua. Os textos que utilizamos para os testes de navegação e leitura se encontravam nos primeiros cadernos. Os critérios de seleção desses textos foram pensados de forma a evitar discrepância de extensão entre eles, além de darmos preferência aos que tivessem estrutura semelhante, mesmo gênero textual, imagens e infográficos de importância similar, certo padrão de linguagem jornalística, poucos ou nenhum problema de revisão e língua portuguesa.

Nas primeiras páginas, optamos por selecionar chamadas com pesos diferenciados, por exemplo, a manchete e uma notícia em "zona morta", de menos importância jornalística. Dessa forma, buscamos selecionar textos diagramados em posições diferentes e cujas matérias em páginas internas fossem o menos discrepantes possível em relação à linguagem, ao tamanho e ao uso de linguagem não-verbal. O obedecimento a esses critérios também visava a evitar demora excessiva nos testes e diferenças muito grandes entre as tarefas

O texto "Inflação de BH é a maior de novo" encontrava-se na página 14 do Primeiro Caderno do Estado de Minas. Na capa do jornal, selecionamos a manchete "Inflação de $\mathrm{BH}$ é 10 vezes maior". A notícia "Saúde de agentes sob ameaça" encontrava-se na página 23 do Gerais, segundo caderno do jornal, em posição de destaque (topo), com foto e legenda. Na capa, a chamada "Zoonoses em más condições", posicionada à direita embaixo, uma "zona morta" do jornal, era compensada por um box com fundo colorido e foto.

O jornal O Tempo apresentava, naquele dia, apenas três cadernos: Primeiro, Cidades e Magazine. Na primeira página, era possível encontrar a chamada para a notícia "Pedestre se arrisca em obra na Antônio Carlos", em posição de pouco destaque, à direita, embaixo. O que compensava 
essa desvantagem era uma foto grande. Nas páginas internas, a notícia selecionada encontrava-se na página B5, no caderno de Cidades. Cobria mais da metade da página e a dificuldade em encontrá-la talvez se devesse ao fato de $O$ Tempo ter paginação alfanumérica (navegação). A segunda notícia de O Tempo, "DRT encontra 24 homens em regime de escravidão", ficava logo abaixo da primeira, sem foto, com texto completo indicado na página interna B6. Ao manipular o jornal, o leitor encontraria a notícia integral na última página do caderno Cidades. Os critérios de seleção dos textos na capa e nas páginas internas do jornal foram os mesmos empregados no Estado de Minas.

Para que o leitor chegasse até as notícias solicitadas, consideramos estratégico:

\section{Escanear a primeira página;}

2. Encontrar a chamada e a indicação de numeração de página interna;

3. Manipular o jornal até chegar à página indicada na capa;

4. Encontrar e ler a notícia.

Para fazer esse percurso, era necessário conhecer o protocolo de navegação dos jornais diários, saber a função de mosaico das capas, buscar a numeração (função hipertextual) e manipular os jornais, observando cadernos e numeração. No entanto, não se pode encontrar a notícia apenas com habilidades de navegação. É necessário fazer uma associação entre o tipo de notícia e a editoria mais pertinente (ou seja, ter desenvolvido habilidades como distinção de temas, assuntos e comparações), assim como converter o título que ela tem na capa do jornal para o título que ela terá internamente (compreensão da proposição).

O Estado de Minas digital apresentava a mesma hierarquização de notícias do impresso. A navegação do jornal dependeria de o leitor escanear a página inicial (home) em busca das chamadas. Isso implica mover a barra de rolagem do site. Daí em diante, ao identificar a chamada da notícia, era necessário clicar no link para ter acesso ao texto integral.

No jornal O Tempo, a notícia sobre as obras na avenida Antônio Carlos mantinha posição semelhante à do impresso, com a mesma foto. Já a notícia sobre trabalho escravo em Minas Gerais não existia na página 
inicial. Nossa hipótese era de que isso poderia representar um embaraço para o leitor, que deveria ir à editoria mais pertinente, no menu à esquerda, e procurar por chamadas internas.

Para que o leitor chegasse até as notícias solicitadas, consideramos estratégico:

1. Escanear a página inicial do site;

2. Encontrar a chamada e o link para página interna;

3. Clicar;

4. Encontrar e ler a notícia.

\subsection{Tarefas e ambiente de pesquisa}

Os testes de navegação e leitura de notícias foram feitos na sala de Ensino à Distância da instituição, onde dispúnhamos de microcomputador com sistema operacional Windows, utilizando o navegador Explorer. As versões impressas dos diários estavam à disposição dos leitores em cima de uma mesa.

Para gravação dos testes em áudio e vídeo dispúnhamos de uma câmera de vídeo parada, em tripé, registrando imagem aberta do leitor e do computador; uma câmera de mão, que forneceria detalhes das mãos e expressões dos rosto; gravador de áudio e microfone, ambos para captação da vOz do estudante.

Cada leitor recebia duas tarefas de navegação e leitura (ver Apêndice 3). O primeiro deles cumpria duas tarefas nos dois jornais e o leitor seguinte recebia as mesmas tarefas, com textos e ambientes trocados, de maneira que pudéssemos avaliar as navegações de todos os textos em ambientes diferentes por todos os participantes. Por exemplo: o Leitor 1 procurava a notícia A no jornal impresso e a notícia B no jornal on-line. O Leitor 2 procurava a notícia A no jornal on-line e a B, no impresso. Essa troca, em ambos os jornais, permitiu que obtivéssemos 2 testes de cada aluno.

A exigência da tarefa proposta aos leitores não era alta: encontrar, na primeira página do jornal, impresso ou digital, determinada chamada (que anunciávamos apenas pelo tema) e adentrar pelo ambiente em busca da matéria completa. Após o cumprimento das tarefas, encontrado o texto, o estudante podia sair da sala dos computadores para responder 
à folha de questões de leitura. É importante frisar que o leitor levava as notícias impressas e podia sempre consultar o texto ao responder às questões. Não restringimos a movimentação dos estudantes e não tínhamos como objetivo verificar se a leitura em ambiente digital é melhor do que a leitura em ambiente impresso. Esse tipo de resposta já foi fornecido por outros pesquisadores (por exemplo, COSCARELLI, 2003) e já se sabe que, quando há diferença qualitativa na leitura nos dois meios, ela é mínima, "um empate técnico". Nossa intenção era verificar diferenciações entre navegar e ler, considerados como níveis ou camadas diferentes do ato de ler.

\subsection{Procedimentos de registro}

O jornal impresso completo, fechado e dobrado foi entregue aos leitores. Enquanto navegava pelo jornal impresso (considerando o percurso feito em busca de uma notícia, da capa à página interna), solicitamos ao leitor que narrasse as ações que executava. Esse protocolo verbal foi gravado em áudio e vídeo e, posteriormente, transcrito. As imagens foram cotejadas com as transcrições e os textos puderam ser complementados com a descrição de gestos e reações. O mesmo foi feito durante a leitura de textos digitais.

Brown e Rodgers (2002) chamam esse tipo de método de introspectivo, já que tenta obter dos informantes seus modos de raciocínio por meio do relato oral ${ }^{9}$. Pressley e Hilden (2004) consideram o método bastante útil e confiável, desde que alguns cuidados sejam tomados pelo pesquisador: explicação simples da tarefa, sem muita orientação; evitar a interrupção do processo para que o leitor não modifique o fluxo normal de leitura; adequação do texto lido à competência leitora do informante.

A modalidade de protocolo verbal utilizada neste trabalho ${ }^{10}$ dá a oportunidade de os leitores falarem sobre o que estão fazendo no instante da atividade, sem atraso, hesitação ou necessidade de memorização. No entanto, a gravação em vídeo nos proporcionou a maior parte dos dados para análise. Notamos que os informantes tinham grande dificuldade de manter o protocolo verbal à medida que manipulavam os textos, tanto no material impresso quanto no digital, pois, à medida que encontravam dificuldades, passavam a dispensar atenção a apenas uma das ações.

No vídeo, pudemos registrar o modo como os leitores lidavam com mouse, cliques, teclado, tela, etc. e como olhavam a tela, subvocali- 
zavam, além de suas expressões e gestos. Cada leitor forneceu à pesquisa um protocolo verbal de navegação para jornal impresso e um protocolo para jornal digital.

\subsection{0 s testes de leitura}

Após a navegação, cada leitor respondeu a um teste de compreensão dos textos composto com base em algumas habilidades descritas na matriz de Língua Portuguesa do Sistema de Avaliação da Educação Básica (Saeb) (ver Apêndices 4 e 5). A Matriz de Referência de Língua Portuguesa volta-se "para a função social da língua" e privilegia as habilidades de leitura. Para isso, busca aferir o conhecimento dos leitores em "diferentes níveis de compreensão, análise e interpretação". Em relação ao teste de Língua Portuguesa, "os descritores têm como referência algumas das competências discursivas dos sujeitos, tidas como essenciais na situação de leitura" (BRASIL, 2007). Em razão da extensão dos textos e do gênero a que pertencem, algumas características das notícias eram mais salientes do que outras, demandando habilidades que nos pareceram mais importantes ou mais evidentes. Dessa forma, optamos por trabalhar a compreensão dos textos a partir de alguns descritores, quais sejam, D1, D2, D11 e D17, conforme detalhamento a seguir:

Tópico I. Procedimentos de Leitura ${ }^{11}$

D1 - Localizar informações explícitas em um texto.

Tópico IV. Coerência e Coesão no Processamento do Texto

D2 - Estabelecer relações entre partes de um texto, identificando repetições ou substituições que contribuem para a continuidade de um texto.

D11 - Estabelecer relação causa/conseqüência entre partes e elementos do texto.

Tópico V. Relações entre Recursos Expressivos e Efeitos de Sentido

D17 - Reconhecer o efeito de sentido decorrente do uso da pontuação e de outras notações. 
Por entender que faltavam dados sobre a compreensão global das notícias, somamos às tarefas de nosso experimento a produção de um resumo escrito. Quanto à escolha dos descritores, D1 nos parecia uma habilidade básica; D2 e D11 apresentavam nível mais complexo; D17 parecia uma habilidade superficial, mas, em textos jornalísticos, algumas notações têm forte presença e são importantes para a marcação de vozes no texto, como se verá em relação ao uso de aspas. O resumo das notícias fazia emergirem a compreensão e mesmo a interpretação das narrativas noticiosas.

\section{Resultados e discussão}

\subsection{Os navegantes}

Os 23 leitores que efetivamente participaram dos testes de navegação geraram resultados que serão aqui analisados por grupos, conforme categorização já mencionada: leitores de jornais impressos, leitores de jornais digitais e não-leitores de jornais.

\subsubsection{Grupo 1}

Os 11 estudantes que faziam parte do Grupo 1 (leitores apenas de jornais impressos) não apresentaram comportamentos discrepantes quando mudaram de ambiente de navegação. Em sua maioria, mostraramse desembaraçados na lida também com jornais digitais, exceto quando dependiam de máquinas de busca, que não sabiam utilizar. Outro indício de que conheciam o objeto de leitura com que lidavam era o relativo conhecimento da nomenclatura utilizada para as partes do jornal. Ribeiro (2003a) já havia mostrado a relação entre o letramento e o conhecimento da nomenclatura utilizada para seções e editorias.

A estratégia de dirigir-se diretamente ao caderno mais pertinente parece importante para a maioria dos leitores deste grupo. Três padrões de comportamento emergiram das leituras: o leitor que escaneia primeiras páginas (no papel ou na tela) e, após essa varredura, "entra" no jornal; o usuário que procura diretamente por cadernos e editorias; e o leitor que prefere folhear (ou navegar a esmo) até encontrar a notícia. Não se pode dizer, no entanto, que haja alinhamento entre as ações do mesmo leitor no 
papel e na tela. Há quem escaneie papel e prefira selecionar abas no jornal digital e há quem faça o contrário.

\subsubsection{Grupo 2}

O Grupo 2 era formado por estudantes que se declararam leitores apenas de jornais digitais e diziam ter pouca experiência na leitura de impressos. Mostraram desembaraço na manipulação dos objetos de ler, tanto impressos quanto digitais. Pareceram-nos mais afoitos em relação às máquinas de busca e menos refinados em suas pesquisas para encontrar as notícias solicitadas.

As operações dos leitores do Grupo 1 (leitores de impressos) e as do Grupo 2 não parecem muito diferentes entre si. O ambiente de leitura em que os estudantes atuam parece fazer pouca diferença em relação às opções que eles selecionam. No entanto, é possível divisar um "vício" maior dos leitores do Grupo 2 em relação às máquinas de busca, assim como um embaraço maior com relação ao conhecimento da interface mosaiquica impressa. No Grupo 2, foi mais comum que os estudantes optassem por folhear o jornal quando se davam conta de que não conheciam o mecanismo de procura dos impressos. Os estudantes conhecem trajetos possíveis para ler jornais, mas nem sempre optam pelos mais rápidos. De qualquer forma, vão fazendo tentativas que terminam, em sua maioria, por levá-los à notícia solicitada.

\subsubsection{Grupo 3}

O Grupo 3 é formado por estudantes que declararam não ler quaisquer jornais, em ambiente algum. Nossa hipótese era a de que não demonstrariam intimidade com a interface hipertextual e se embaraçariam mais do que os leitores dos Grupos 1 e 2. No entanto, o Grupo 3 comporta desde estudantes que cumpriram as tarefas propostas e apresentaram alguma noção da leitura em composições mosaiquicas, até estudantes que se mostraram bastante distanciados do processo de ler hipertextos, tanto faz se em papel ou em tela. Nestes grupos, os estudantes têm alguma noção dos protocolos projetados e não chegam a se mostrar completamente alheios à maneira como se procede na busca por uma notícia. De fato, o Grupo 3 foi o que mais apresentou navegantes com dificuldades de cumprir a tarefa solicitada, mas também foi o único em que os estudantes sentiam muita necessidade de se explicar, de "pedir desculpas" pela pouca habilidade com as interfaces. 
O trajeto proposto pela pesquisa, que parecia tão pouco exigente, agora mostra que as nuances entre os leitores, mesmo para cumprir algo tão aparentemente simples, são muitas, e todas elas dependem de experiências de leitura e de letramento das quais nem mesmo os próprios leitores têm consciência.

\subsection{Leitura e compreensão dos textos}

Todos os grupos fizeram testes de habilidades de leitura das notícias que encontraram depois de navegar. Procederemos à análise dos resultados da leitura de cada grupo, por Descritor, já que, caso as análises fossem feitas por grupos, ficariam muito repetitivas.

\subsubsection{Localização de informações (D1)}

Todos os testes de leitura, referentes aos quatro textos de jornais nos dois ambientes (impressos e digitais), foram respondidos adequadamente $^{12}$ por todos os estudantes, dos três grupos. Esse bom desempenho era, na verdade, esperado, já que tratávamos com estudantes universitários e essa habilidade é considerada básica.

\subsubsection{Estabelecimento de relações entre partes de um texto (D2)}

Para a compreensão dos textos, eram necessárias algumas inferências de tipo conectivo (COSCARELLI, 1999), que favoreciam a compreensão do todo. Dos 23 leitores, 11 leram notícias do Estado de Minas, sendo que deles, 10 responderam corretamente à questão composta com base em D2. Os estilos de resposta variaram, dos mais detalhados aos mais objetivos. No mesmo jornal, com relação ao texto "Zoonoses em más condições", 9 leitores deram respostas adequadas à questão D2.

Também dos 9 leitores do jornal O Tempo, 8 responderam satisfatoriamente à questão proposta para "Pedestre se arrisca em obra na Antônio Carlos". Em relação ao texto "DRT encontra 24 homens em regime de escravidão", apenas 4 deram resposta satisfatória. Os demais estudantes apresentaram respostas evasivas ou não resolveram a questão. Embora a habilidade descrita fosse idêntica, o grau de dificuldade da questão era maior para o segundo texto, o que se refletiu no desempenho dos leitores. 


\subsubsection{Estabelecimento de relaç̃ões de causa e consequência (D11)}

Para esta habilidade, a maioria dos estudantes demonstrou mais dificuldade, oferecendo respostas inadequadas ou simplesmente deixando em branco. A complexidade da habilidade demandada pela questão parece prevalecer em relação a perfis de grupos de leitores. Até o momento, a pesquisa demonstrou que a dificuldade de ler geralmente não estava relacionada à dificuldade de navegar. Os comportamentos de navegação de grupos de não-leitores, leitores de jornais impressos e digitais não apresentaram padrões nítidos, assim como a uma pretensa diferenciação entre navegantes contumazes e leitores analógicos não se mostrou adequada em relação à compreensão de textos. Não-leitores de jornais que demonstraram grande dificuldade de navegação apresentaram bom desempenho em níveis mais complexos de compreensão de texto. $\mathrm{O}$ contrário também ocorreu.

\subsubsection{Reconhecimento de efeitos de sentido construídos com base em usos da pontuação ou do emprego de notações (D17)}

Em geral, o emprego das aspas em notícias marca os depoimentos das fontes, tais como pessoas envolvidas no caso, autoridades, especialistas, ou seja, o gerenciamento das diversas vozes do texto é sistematicamente marcado por essa notação. A habilidade de construir sentido com base nessas marcações está vinculada a outras habilidades (não tratadas aqui), como distinguir fatos de opiniões ou perceber opiniões diferentes no texto, de maneira que não ter desenvolvido uma delas pode prejudicar a compreensão do texto inteiro, caso o leitor não domine o sentido das notações.

As respostas consideradas adequadas para esta questão eram, para todos os casos, a marcação de depoimentos de fontes ou a diferenciação da voz do narrador e de outras pessoas, depoimentos, etc. Dos 11 leitores do Estado de Minas, para o texto sobre a inflação em Belo Horizonte, 6 responderam corretamente à questão. Os 5 leitores que não deram respostas satisfatórias incorreram no engano de não focalizar o ponto mais adequado ao uso das aspas no contexto, embora pudessem indicar outros usos dessa notação. Sobre a notícia "Zoonoses em más condições", 7 leitores identificaram a função adequada para o emprego das aspas, enquanto outras 4 respostas foram consideradas inadequadas, por fugirem completamente à função de marcação de vozes no texto. 
As leituras dos textos do jornal O Tempo foram as que mais apresentaram problemas principalmente porque a maior parte dos leitores não reconheceu as funções das aspas em notícias. No texto sobre as obras na avenida Antônio Carlos, dos 9 leitores, apenas 2 deram respostas consideradas satisfatórias, apontando o uso de aspas para marcar depoimentos e vozes diferenciadas da do jornalista. Os demais participantes ofereceram respostas inadequadas ao contexto.

No texto sobre trabalhadores em regime de escravidão, dos 9 leitores, a confusão se desfez para 6. Apenas 3 confirmam alguma dificuldade em perceber com clareza o uso de aspas no texto. Embora muitos estudantes mencionassem, em suas respostas, usos de aspas tais como "fazer ironia" ou "palavra em língua estrangeira", não encontraram resposta adequada para a questão proposta, que demandava conhecimentos sobre citações diretas. Pareceu-nos que grande parte desses leitores "aprendeu", ao longo da vida, certos usos dessa notação, mas não podia reconhecê-los em seus contextos.

\subsubsection{Sumarização de texto}

Analisando a matriz de Língua Portuguesa do Saeb, consideramos problemática a ausência de um descritor que verificasse a habilidade de compreensão global do texto. Por isso, propusemos um resumo da notícia.

Nossa avaliação dos resumos produzidos pelos leitores utilizou critérios como: a) se as linhas principais da narrativa do texto original estavam presentes; b) se o estudante distinguia elementos principais de secundários; c) se a hierarquia das informações vinha "colada" ao texto original ou se havia elaboração; d) se havia pertinência entre o lido e o texto (ausência de "achismos", opinião pessoal, tendência à digressão). A habilidade de sumarização que queríamos verificar está intimamente relacionada a descritores mais específicos, como identificar o tema e a tese de um texto, sendo capaz de distinguir argumentos e/ou perceber partes secundárias e partes principais.

A maioria dos estudantes mostrou-se capaz de produzir resumos das notícias, no entanto, foi notável a diferença entre sumarizações em que o leitor reformulava a macroestrutura textual, revelando inferências e, de fato, compreendendo o texto, até as sumarizações em que o leitor não conseguia se descolar de repetições literais (ou quase) do texto original ${ }^{13}$. 
Em todos os grupos de estudantes isso ocorreu, não havendo padrões relacionados à preferência por jornais impressos ou digitais, nem mesmo havendo distinção entre perfis de navegação. As sumarizações de todos os textos, de ambos os jornais, apresentaram problemas da mesma ordem, não havendo também padrões perceptíveis entre Estado de Minas e $O$ Tempo impressos ou digitais.

\section{Considerações finais}

Os dados gerados pelos testes de navegação e leitura, em todos os grupos (impressos e digitais, em ambos os jornais trabalhados), sugerem diferenças de desempenho de leitura mais relacionadas à ausência de determinadas habilidades leitoras, independentemente de os textos serem apresentados em meio impresso ou digital. Os fatores que parecem preponderantes estão mais relacionados, no caso desta pesquisa, a questões como:

dificuldades percebidas pelo leitor no texto: palavras desconhecidas, nãoreconhecimento de emprego de marcações e sinais, falta de conhecimento prévio sobre aspectos da História, por exemplo;

pouco reconhecimento de aspectos significativos da composição dos textos nas páginas, como é o caso de leitores que não compreendem fios, boxes e fundos reticulados como indícios de que os textos ali diagramados são secundários em relação ao texto da notícia principal. Essas hierarquias nem sempre são percebidas ou conhecidas pelo/do leitor.

Fazendo-se um cruzamento entre as declarações dadas pelos leitores no questionário inicial da pesquisa, os testes de navegação e os testes de leitura (com base no Saeb), pudemos verificar que leitores cujas experiências letradas (declaradas ${ }^{14}$ ) são mais numerosas e variadas, na escola ou fora dela, apresentam melhores desempenhos de navegação (tanto no jornal impresso quanto no digital) e de leitura nos testes, com poucas exceções. Há os casos discrepantes em que leitores que se declararam usuários frequentes de jornais tiveram maus resultados nos testes, assim como há os casos de pessoas que se disseram pouco afeitas à leitura de jornais em qualquer ambiente, no entanto, demonstraram capacidades avançadas de navegar em jornais e de ler notícias. Casos 
extremos como os mencionados serão analisados mais dedicadamente em outros trabalhos, com base em estudos de letramento visual, design e legibilidade.

O fato de não haver, ao menos entre os dados gerados por esta investigação, grandes diferenças entre leitores de jornais em telas ou no papel é apenas uma confirmação de pesquisas que já têm sido feitas. $O$ que se observou nos comportamentos dos leitores participantes desta pesquisa é que, de modo geral, parecem explorar as interfaces que têm diante de si, mesmo não demonstrando intimidade com elas ${ }^{15}$. Outro dado interessante diz respeito ao fato de grande parte dos leitores demonstrarem que habilidades de navegar e de ler são camadas diferentes de letramento (seja no papel, seja na tela), importando muito que ambas se retroalimentem. Vários leitores demonstraram ser possível navegar bem e não atingir bons resultados para diversas habilidades de leitura das notícias. Outro grupo de leitores demonstrou dificuldades de navegar nas interfaces em busca de textos, no entanto, ao encontrá-los, podiam ler com compreensão as notícias do dia. É interessante destacar que os próprios leitores não têm consciência de seus graus de letramento, inclusive o digital. Ao fazerem afirmações sobre sua capacidade de ler jornais, não têm noção de seus desempenhos reais diante dos diários e das notícias.

Habilidades para lidar com interfaces e habilidades propriamente de leitura (linguísticas) parecem extratos distintos da leitura, algo que provavelmente um pesquisador da Semiótica tomaria como o óbvio. Estamos falando, então, de uma sobreposição de habilidades de leitura de textos escritos (ou, melhor, uma interpolação delas) que deveriam ser desenvolvidas de maneira integrada, e aqui queremos nos referir principalmente àqueles aspectos do texto que a Linguística insiste em chamar de "extratextuais". As combinações de letramentos são muitas e surtem efeitos também combinatórios.

Com isso, queremos dizer que todo objeto de ler (o texto no suporte ou o nome que tenha) é complexo e é composto por uma série de sobreposições tecnológicas às quais o leitor também responde (ou não) com outras sobreposições (de letramento). Em algum ponto das propostas de formação das agências de letramento (especialmente a escola), não se tem mostrado ao leitor em formação como operar interfaces, com honrosas exceções. Embora o texto, de preferência o bom 
texto, venha sendo assunto escolar, os suportes onde ele está inscrito nem sempre são. Os "modos de usar" ficam sempre de fora da "receita". Não é de hoje que as pessoas estudam textos fora das plataformas em que foram publicados. Talvez esse seja um dos nós que as levam, em alguns casos, a não reconhecer indícios significativos de leituras que dependem, também, da diagramação e da organização dos textos nas páginas, analógicas ou digitais.

Coscarelli (2003, p. 1) não acredita que "um conjunto de textos interligados por meio de links" poderia ter tantos motivos para ser tão diferente dos textos "comuns" em relação aos processos da leitura. Não parece haver nada de tão novo na leitura do hipertexto, ao menos em relação à ativação de habilidades de leitura necessárias em qualquer ambiente. Embora o projeto das interfaces tenha mudado, o leitor não parece acompanhar, sempre, tais alterações. Mostra-se capaz de aprender a leitura em telas antes mesmo de se familiarizar com suportes de papel, assim como parece poder navegar sobre um mar de sentidos que ele não conhece; ou, ao contrário, chegar aos sentidos mesmo tendo encontrado obstáculos na lida com o suporte. Em um “sistema de mídia” aberto como o nosso, não faltará tarefa para o professor atento às configurações do letramento.

\section{Agradecimentos}

Carla Viana Coscarelli (Poslin, UFMG), Fábio Alves da Silva Júnior (Poslin, UFMG), Diretores e coordenação de Língua Portuguesa (especialmente prof. Rogério Barbosa da Silva) do CEFET-MG, Ana Cristina Ribeiro, Ricardo Rabelo, Jorge Rocha, alunos do curso de Enfermagem da UNA, assim como coordenadores e gestores; coordenadores do laboratório de cinema e vídeo da UNA; Natália Lanza (orientanda de Iniciação Científica); profa. Maria José Agostini.

\section{Referências}

ALVES-MAZZOTTI, Alda Judith. Usos e abusos dos estudos de caso. Cadernos de Pesquisa, v.36, n.129, p. 637-651, set./dez. 2006.

ANGIOLILLO, Francesca. Brasileiro não encontra prazer na leitura. Folha de S.Paulo, p. E8, 14 de julho 2001. Ilustrada,.

BOLTER, Jay D; GRUSIN, Richard. Remediation. Understanding new media. USA: MIT Press, 2000.

BRASIL. O que é o Saeb? Sistema de Avaliação da Educação Básica. INEP, 2007. Disponível em: <http://www.inep.gov.br/basica/saeb/caracteristicas.htm>. Acessado em 7.6.2007. 
BRIGGS, Asa; BURKE, Peter. Uma história social da mídia: de Gutenberg à Internet. Trad. Maria Carmelita Pádua Dias. Rio de Janeiro: Jorge Zahar, 2004.

BROWN, J. D.; RODGERS, T. Doing second language research. Oxford: Oxford, 2002. (Caps. 1, 2, 3).

CANAVILHAS, João Messias. Webjornalismo - Considerações gerais sobre jornalismo na web. Biblioteca On-line de Ciências da Comunicação, 2001, Disponível em:

$<$ http://www.bocc.ubi.pt/_esp/autor.php?codautor=602>. Acessado em dez. 2006.

CHARTIER, Roger. Cultura escrita, literatura e história: Conversas de Roger Chartier com Carlos Aguirre Anaya, Jesús Anaya Rosique, Daniel Goldin e Antônio Saborit. Porto Alegre: Artmed, 2001a.

CHARTIER, Roger. Textos, impressão, leituras. In: HUNT, Lynn. A nova história cultural. 2 ed. Trad. Jefferson Luiz Camargo. São Paulo: Martins Fontes, 2001b.

COLlARO, Antonio Celso. Projeto gráfico. Teoria e prática da diagramação. 4 ed. São Paulo: Summus, 2000. (Novas buscas em Comunicação)

COSCARELLI, Carla Viana. Leitura em ambiente multimídia e produção de inferências. 1999. 322 f. Tese. (Doutorado em Estudos Linguísticos). Faculdade de Letras, Universidade Federal de Minas Gerais, Belo Horizonte, 1999.

COSCARELLI, Carla V. Espaços hipertextuais. Anais do II Encontro Internacional Linguagem, Cultura e Cognição, jun. 2003, FAE - UFMG, BH. Coord.: Eduardo Fleury Mortimer, Ana Luiza B. Smolka. (CD- ROM)

KLEIMAN, Angela B. (Org.) Os significados do letramento: uma nova perspectiva sobre a prática social da escrita. Campinas, SP: Mercado de Letras, 1995. (Coleção Letramento, Educação e Sociedade)

KLEIMAN, Angela B. Leitura: ensino e pesquisa. 2 ed. Campinas, SP: Pontes, 2004.

LÉVY, Pierre. As tecnologias da inteligência. O futuro do pensamento na era da informática. Trad. Carlos Irineu da Costa. Rio de Janeiro: 34, 1993. (Coleção TRANS)

MIELNICZUK, Luciana. Características e implicações do jornalismo na web. II Congresso da SOPCOM, Lisboa, 2001. Disponível em:

<http://www.facom.ufba.br/jol/pdf/2001_mielniczuk_caracteristicasimplicacoes.pdf > . Acessado em dez. 2006.

MIELNICZUK, Luciana. A Pirâmide Invertida na época do Webjornalismo: tema para debate. XXV Congresso Brasileiro de Ciências da Comunicação, INTERCOM - Sociedade Brasileira de Estudos Interdisciplinares da Comunicação, Salvador/BA, 1 a 5 set 2002. MIELNICZUK, Luciana. Webjornalismo de terceira geração: continuidades e rupturas no jornalismo desenvolvido para a Web. XXVII Encontro dos Núcleos de Pesquisa da INTERCOM - Sociedade Brasileira de Estudos Interdisciplinares da Comunicação, Porto Alegre, 2004. Disponível em:

<http://reposcom.portcom.intercom.org.br/handle/1904/17332>. Acessado em dez. 2006.

MIELNICZUK, Luciana. O desafio de aprender e de ensinar edição para webjornais. In FELIPPI, Ângela; SOSTER, Demétrio de Azeredo; PICCININ, Fabiana (Orgs.). Edição em jornalismo. Ensino, teoria e prática. Santa Cruz do Sul: Edunisc, 2006.

POSSENTI, Sírio. A leitura errada existe. In: BARZOTTO, Valdir Heitor (Org.). Estado de leitura. Campinas, SP: Mercado de Letras; Associação de Leitura do Brasil, 1999. (Coleção Leituras do Brasil). 
PRESSLEY, Michael; HILDEN, Katherine. Verbal protocols of reading. In: DUKE, Nell K; MALLETTE, Marla H. Literacy research methodologies. New York: Guilford Press, 2004.

RIBEIRO, Ana Elisa F. Ler na tela - novos suportes para velhas tecnologias. 2003. 112 f. Dissertação. (Mestrado em Estudos Linguísticos, Inter-relações entre linguagem, cultura e cognição). Faculdade de Letras, Universidade Federal de Minas Gerais, Belo Horizonte, $2003 a$.

SANTAELLA, Lucia. Antecedentes da Alinearidade hipermidiática nas mídias mosaiquicas. In: BRASIL, André et al. (Orgs.) Cultura em fluxo: novas mediações em rede. Belo Horizonte: Editora PUC Minas, 2004a.

SILVA, Maria Stella Rangel. O jornal é um hipertexto?, $1^{0}$ Seminário Nacional O professor e a leitura do jornal, 2002. Disponível em:

<http://www.acordeduca.com.br/ezequiel/comunicacoes/O $\% 20 J O R N A L \% 20 \%$ C3\% 89\%20UM\%20HIPERTEXTO.htm>. Acessado em 11.12.2006.

SNYDER, Ilana. A new communication order: researching literacy practices in the network society. Language and Education, v.15, n.2-3, p. 117-131, 2001.

SOARES, Magda. Novas práticas de leitura e escrita: letramento na cibercultura. Educação e Sociedade, Campinas, v.23, n.31, p. 143-160, dez. 2002.

TFOUNI, Leda Verdiani. Letramento e alfabetização. 6. ed. São Paulo: Cortez, 2004. (Coleção Questões da Nossa Época; v.47)

\section{APÊNDICE 1}

\section{ESTAD0 DE MINAS}

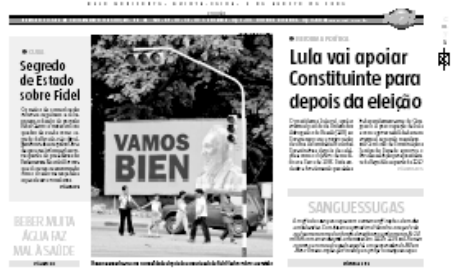

Inflação de BH é 10 vezes maior

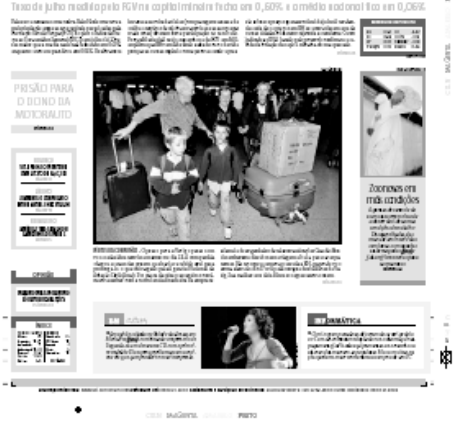

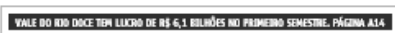
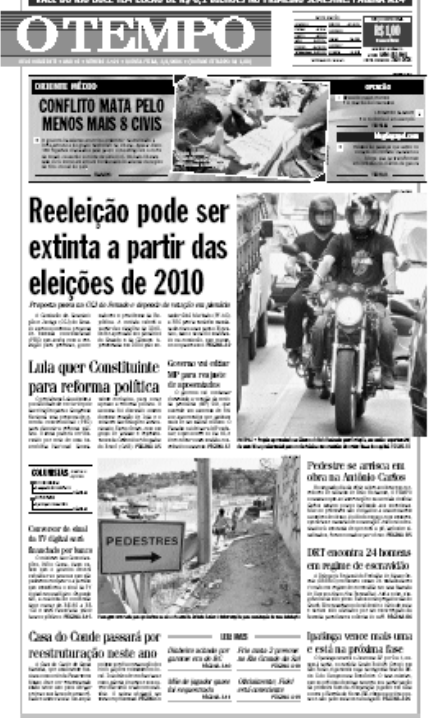

Reprodução dos jornais impressos Estado de Minas e 0 Tempo, de 5 de agosto de 2006. 
APÊNDICE 2

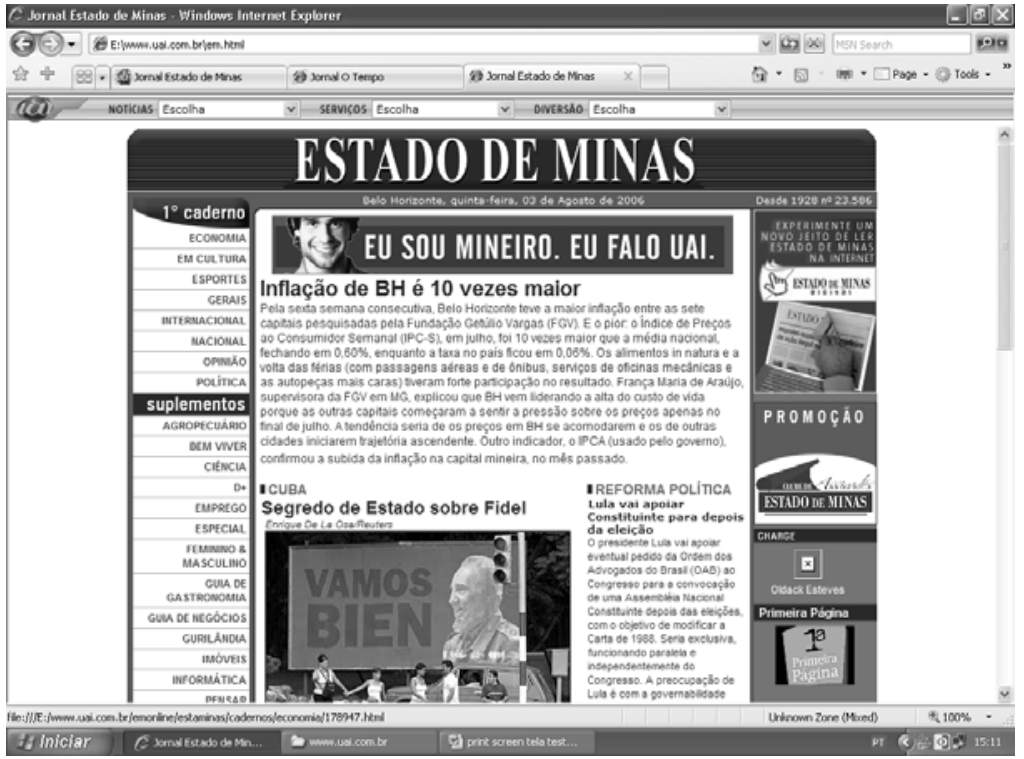

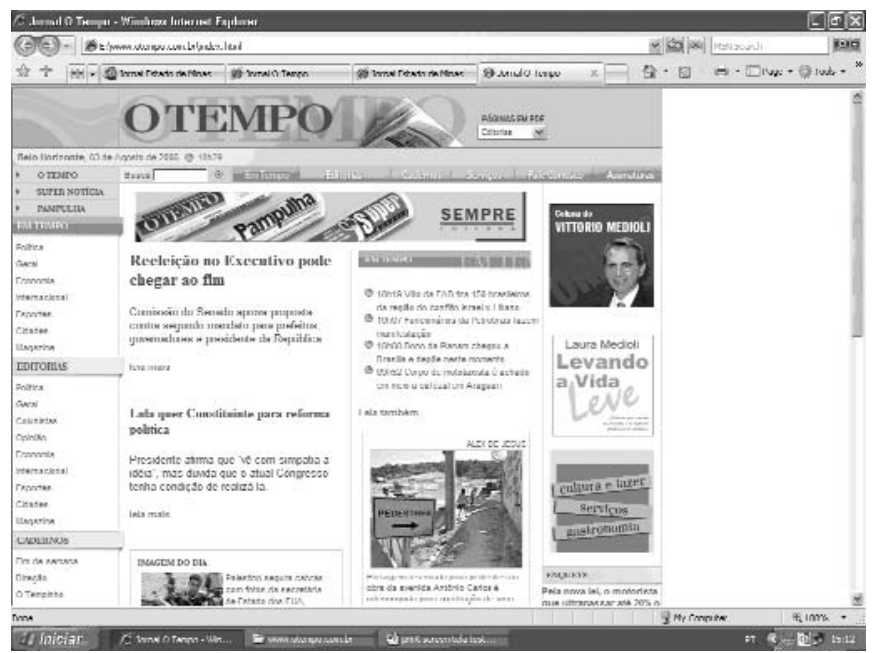

Print Screen dos jornais digitais Estado de Minas e 0 Tempo, de 5 de agosto de 2006. 


\title{
APÊNDICE 3
}

Tarefas de navegação.

\section{NAVEGAÇÃO EM JORNAIS IMPRESSOS E DIGITAIS RELAÇÕES ENTRE LEITORES E INTERFACES}

\author{
OBRIGADA POR PARTICIPAR DA NOSSA PESOUISA
}

\section{O TEMPO}

\section{TAREFA 1}

Encontre no jornal uma notícia sobre a inflação em BH. Leia a notícia para responder a algumas questões.

\section{TAREFA 2}

Encontre no jornal uma notícia sobre problemas no setor de zoonoses da cidade.

Leia a notícia para responder a algumas questões.

\section{O TEMPO}

\section{TAREFA 1}

Encontre no jornal uma notícia sobre trabalho escravo.

Leia a notícia para responder a algumas questões.

\section{TAREFA 2}

Encontre no jornal uma notícia sobre obras na Antônio Carlos.

Leia a notícia para responder a algumas questões. 
APÊNDICE 4

Reprodução das notícias dos jornais.

\section{Índice atinge 0,6\% em julho na capital, 10 vezes acima da média nacional de 0,06\%, puxado pelos alimentos in natura}
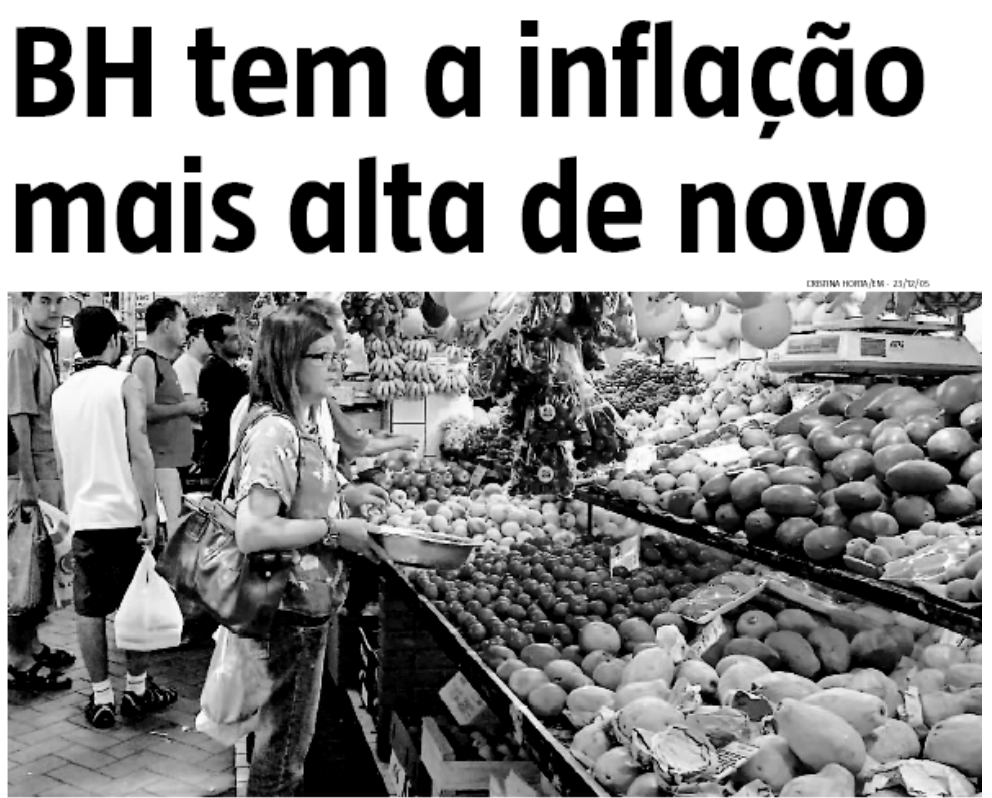

Banca do Mercado Central: mamäo papaia liderou os aumentos de preços, ao disparar $125,56 \%$ no mès passado, em relaçăo a junho

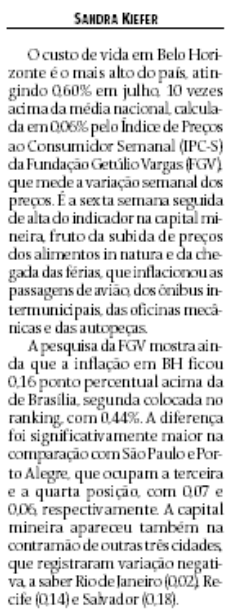

Franca Maria de Araújo super- dicador, o Índice de Precos ao visora da FV em Minas observa Consumidor Amplo (IIFCA) $O$ inque a inflaçâo da capital mineira dice que se situahistoricamente quiu na frenté em relaçio âs out- em patamar mais baixo em relasaiu na frente em relaçao ás ou- em patamar mais baixo em relatras capitais que so começaram a çáo ao IFC-S, fechou o mès em
sentircs aumentos de precos mofi- $030 \%$ segundo divulgado ontem sentircs aumentos de precos nofi- $030 \%$ segundo divulgado ontem
nal do mès passado. "A partir de
pela Fundaçáo Instituto de Pesagora os preoos tendem a se ậ- quisas Econốnicas Administratimodar em BH ea iniciar trajetória vase Contabeis de Minas Gerais ascendente ns outras cimco dida- (Fundaçāo Ipead) da UFMG. Nodes' compara a pesquisadora Ela vamente os alimentos nào indusatribuiaalta nacapital minerianos trializados foram os principais alimentos in ratura com destaque resporsiveis pela alta comdestaalimentos in natura com destaque resporsáveis pela alta corndesta-
para o preco do mamáo papaia que para a cenoura $(2640 \%)$ e o $\begin{array}{ll}\text { para o preç do mamão papaia } & \text { que para a cenoura }(26,40 \%) \text { e o } \\ \text { que saltou } 125,59 \% \text { em julho, na } & \text { arroz }(364 \%) \text { além do mesmo }\end{array}$ comparaçāo comn o mês anterioc. O mamãa segundo as Centrais de Abastecimento de Minas Gerais (Ceasa Minas) além de estar no perícdo da entressafra,enfrentou problemas com a seca no Sul da Bahia e no Norte do Fspirito Santo regióes que abasteơm os Santo regiōes que abastecem os
sacolóes e supermercados de BH -O irverno seco afetou a produçào do marnâo que já sente muito com ofrio 0 produto além de ter caido a oferta caiu tambén

REFORCO Ainflacio tambếnsu-

REFORÇO Ainflaçio também su-
biu em Belo Horizonte em julho conforme a mediçào de outro in- arroz $(364 \%)$ além do $\mathrm{n}$
marmão papaia $(85,54 \%$.

Wanderky Ramalhn diretor da Fundaçio lpead considera que a elevaçáo da inflaçâo em BH não chega a preccupar jáque o indice apresentou queda de $036 \% \mathrm{em}$ apresentou queda de $036 \%$ em junho e de $0,18 \%$ em maio "Nao
se pode dizer que co precos estão se pode dizer que cos preças estão
em alta mas sim que pararam de cair', afirma Segundo a projeção da Fundaçao Ipead feita corm basenoacumuladoaté agora (235\%) e no comportamento do indicador no ano passado a previsâo é dor no ano passado a previsáo é
de que a inflaçáo em $\mathrm{BH}$ atinja de que a inflação em BH atinja $427 \%$ em 2006 ficando abaixo da
meta de $45 \%$ estabelecida pelo Banco Central.

\section{EFEITO SACOLĂO \\ INFLACAO MEDIDAPELO

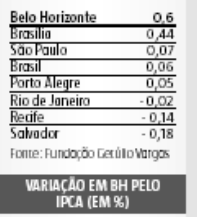

IPCABH 0,3

Maiores altas

Marnao

Plamoura de saúde

Ancr

Maiores baisas

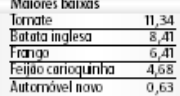

Autcrnóvel now 0,63 
Açōes como o combate à leishmaniose em Belo Horizonte são feitas por funcionários da prefeitura, que nằ têm equipamentos de proteçäo individual para aplicar inseticidas

\section{Saúde de agentes sob ameaça}

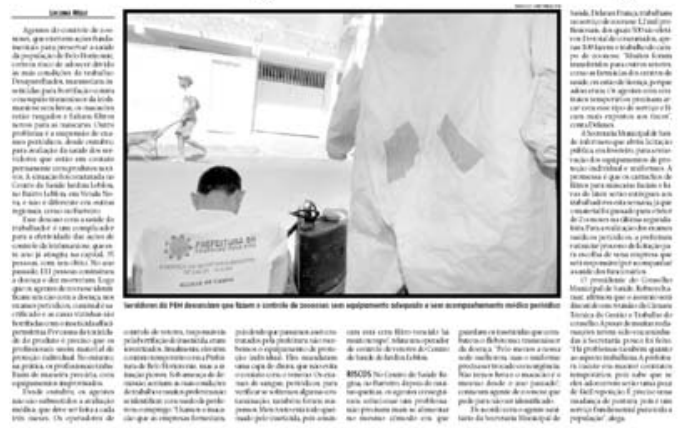

\section{Pedestre sofre com obra na Antônio Carlos}

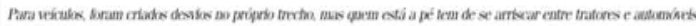
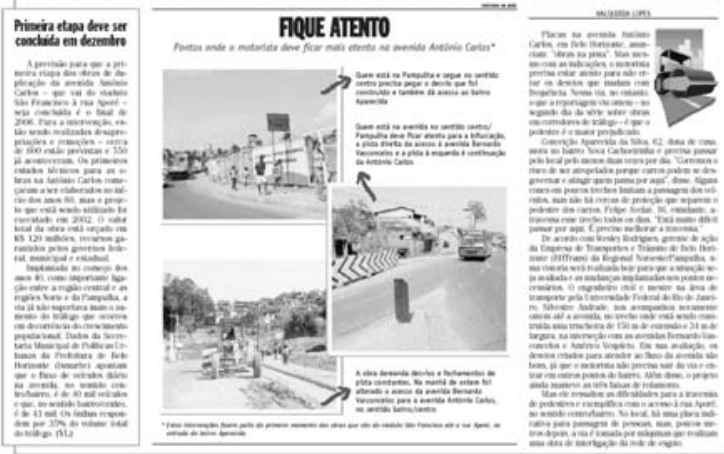

\section{DRT flagra 24 homens em regime escravo}

Vindos do Ceará, trabalhadores colhiam café em fazenda no municiplo de Campos Altos, em Minas

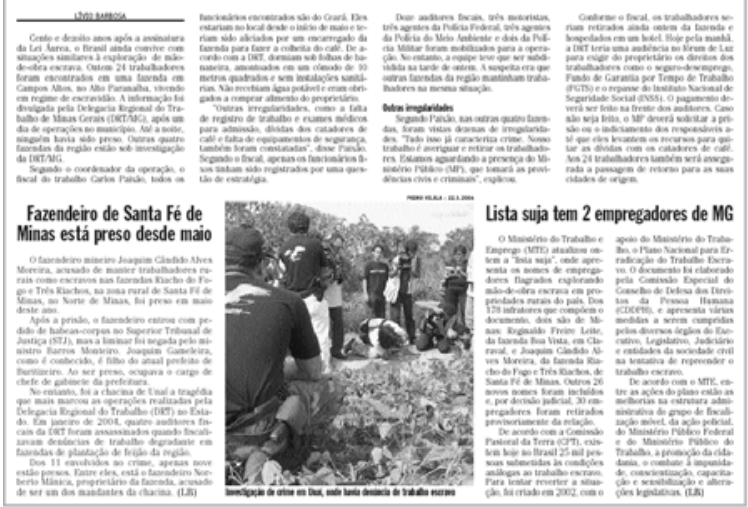




\section{Notas}

${ }^{1}$ Soares (2002) menciona os "protocolos de leitura" como uma possibilidade criada pela progressiva organização dos textos, ao longo da história do livro, em partes, capítulos, páginas, etc.

${ }^{2}$ Os links tratados aqui são estes que aparecem marcados em palavras no texto. Há, no entanto, outros, dos quais se fala menos: aqueles interfaceados por botões, teclas, setas, etc. Como estes não estão no texto, ficam em segundo plano, atuando apenas como recursos da programação de uma página eletrônica.

${ }^{3}$ Embora haja uma discussão, especialmente nas ciências da Comunicação, sobre uma diferenciação entre jornalismo digital, jornalismo on-line e webjornalismo, não faremos distinção entre uns e outros neste trabalho. Para conhecer reflexões sobre essa nomenclatura e sobre práticas do fazer jornalístico, ver, por exemplo, Mielniczuk (2001; 2002; 2004; 2006) e Canavilhas (2001).

${ }^{4}$ Os resultados gerados pelos questionários foram publicados em Informática Pública, ano 9, n. 2, dez. 2007, no artigo "Letramento digital de estudantes universitários: estudo de caso”. Os mesmos resultados, interpretados sob viés mais adequado à área de saúde, estão submetidos à revista Saúde e Sociedade.

${ }^{5}$ Ver Educação em Revista n. 40, dez. 2004. O texto é "Letramento digital - lendo em papel e em pixel".

${ }^{6}$ Os testes de usabilidade são feitos em laboratórios onde leitores reais são filmados e suas navegações são gravadas em softwares específicos, para posterior avaliação pelos engenheiros. A intenção é obter auxílio do próprio usuário para a produção de interfaces melhores e mais "usáveis". No entanto, esses testes não abordam aspectos psicolinguísticos do processamento leitor.

${ }^{7}$ Mielniczuk (2001) propõe uma espécie de categorização para os modos de fazer jornalismo surgidos na internet, com base em experiências com o novo ambiente. Jornais "transpositivos" seriam aqueles que apenas migram suas notícias do impresso para o meio digital, sem se apropriar de qualquer possibilidade que o novo meio ofereça (interatividade, customização, memória, etc.). Jornais "metafóricos" se apropriam um pouco mais do novo ambiente, mas continuam a se planejar sob a metáfora do impresso. Os webjornais, sim, seriam feitos para a internet e costumam sem dispor de versão impressa.

${ }^{8}$ Collaro (2000) chama de "zona morta" os espaços menos visíveis da organização da página diagramada, tais como posições embaixo, à esquerda, que são as últimas que olhamos quando lemos. Alguns projetos de design dão soluções com cores e imagens para compensar a desvantagem da posição.

${ }^{9}$ Tais métodos aparecem, na obra de Brown e Rodgers (2002), com os nomes think-aloud, talk-aloud e estudo retrospectivo, mais ou menos como sinônimos.

${ }^{10}$ Pressley e Hilden (2004) mencionam o protocolo verbal em que o leitor reporta o que foi feito após a leitura. Nesse caso, os autores apontam a interferência da interpretação que o leitor dá aos processos que executa. O protocolo verbal feito durante a leitura depende de memória de trabalho e, portanto, parece ser mais direto. 
${ }^{11}$ Disponível em: <http://www.inep.gov.br/basica/saeb/caracteristicas.htm>. Acesso em 7.6.2007.

${ }^{12}$ Com base em Possenti (1999), construímos um "gabarito" de respostas autorizadas às questões propostas para cada texto. Tratando-se de notícias jornalísticas, pudemos considerar que houvesse leitura mais adequada. As leituras desautorizadas pelo texto foram consideradas "inadequadas".

${ }^{13}$ As estratégias cognitivas da sumarização são bem explicadas e discutidas por Kleiman (2004).

${ }^{14} \mathrm{E}$ importante frisar que os leitores fizeram declarações às pesquisadoras com base em suas autoavaliações do que seja ler muito, ler pouco, ter hábito de ler. Esse tipo de declaração apresenta problemas de confiabilidade, dada a subjetividade das respostas e até mesmo a necessidade que alguns leitores têm de camuflar seus verdadeiros hábitos. Há leitores que se dizem frequentes para "agradar" as pesquisadoras, assim como há aqueles que demonstram modéstia excessiva ao tratar de suas vidas com a leitura.

${ }^{15}$ Para mais detalhes sobre esta investigação, apenas ligeiramente resumida aqui, ver a tese Navegar lendo, ler navegando: aspectos do letramento digital e da leitura de jornais, já disponível na internet. Vários trabalhos derivados da tese já foram publicados e outros deverão refinar e rever as análises feitas.

Recebido: $13 / 08 / 08$

Aprovado: 13/04/09

Contato:

Centro Federal de Educação Tecnológica de Minas Gerais (CEFET/MG) Av. Amazonas, 5253 - Nova Suiça

Belo Horizonte - MG

CEP 30480-000 